\title{
Neighborhood Socioeconomic Status and Cognitive Function in Women
}

\author{
RA Shih ${ }^{1}$, B Ghosh-Dastidar ${ }^{1}$, KL Margolis $^{2}$, ME Slaughter ${ }^{1}$, A Jewell ${ }^{1}$, CE Bird ${ }^{1}$, C Eibner ${ }^{1}$, \\ NL Denburg ${ }^{3}$, J Ockene ${ }^{4}$, CR Messina ${ }^{5}$, and MA Espeland ${ }^{6}$ \\ ${ }^{1}$ RAND Corporation, Arlington VA \\ ${ }^{2}$ HealthPartners Research Foundation, Minneapolis MN \\ ${ }^{3}$ University of lowa, lowa City, IA \\ ${ }^{4}$ University of Massachusetts, Worcester, MA \\ ${ }^{5}$ Stonybrook University, Stonybrook, NY \\ ${ }^{6}$ Wake Forest University School of Medicine, Winston-Salem, NC
}

\begin{abstract}
Objectives-We examined whether neighborhood socioeconomic status (NSES) was associated with cognitive functioning in older US women, and whether this was explained by associations between NSES and vascular, health behavior, and psychosocial factors.
\end{abstract}

Methods-Women ages 65-81 (N=7,479) free of dementia enrolled in the Women's Health Initiative Memory Study. Linear mixed models examined the cross-sectional association between an NSES index (0-100) and $\log _{\mathrm{e}}$-transformed cognitive functioning scores. A base model adjusted for age, race/ethnicity, education, income, marital status, and hysterectomy. Three groups of potential confounders were examined in separate models: vascular, health behavior, and psychosocial factors.

Results-Living in a neighborhood with a one-unit higher NSES value was associated with 0.022 standard deviations higher cognitive function $(p=0.02)$. The association was attenuated but still marginally significant $(p<0.10)$ after adjustment for confounders and, based on interaction tests, stronger among younger and non-white women.

Conclusions-The socioeconomic status of a woman's neighborhood may influence cognitive function. This relationship is only partially explained by vascular, health behavior, or psychosocial factors. Future research will examine the longitudinal relationships between NSES, cognitive impairment and cognitive decline.

\section{Keywords}

neighborhood socioeconomic status; cognitive function; women

\footnotetext{
Corresponding Author: Regina A. Shih, Ph.D., 1200 S. Hayes St. Arlington VA 22202, rshih@rand.org.

Contributor Statement: RAS, BGD, KML, and MAE designed the study and directed its implementation; RAS, BGD, MES and MAE designed the study's analytic strategy; RAS conducted the literature review and prepared the initial drafts of the article; and BGD, KML, MES, AJ, CEB, CE, NLD, JO, CRM, MAE reviewed and revised various sections of the article for intellectual content.

Human Participant Protection: The study was approved by the investigators' institutional review boards, and each participant signed a written informed consent form to participate in the study.
} 


\section{INTRODUCTION}

A growing body of research suggests that the characteristics of neighborhoods in which individuals live may influence risk for poor self-rated health, cardiovascular disease, and mortality, above and beyond individual-level characteristics (1-15). The proposed mechanisms by which lower quality neighborhoods may influence poor physical health include exposure to chronic stressors and pollutants in the environment; increased access to alcohol and cigarette outlets; barriers to physical activity; reduced social support, networks, and cohesion; and reduced access to high quality health and social services. Three recent studies have linked lower neighborhood socioeconomic status (NSES) with lower cognitive function in UK adults older than 52 years (16), US adults older than 70 years living in urban areas (17), and Mexican Americans older than 65 living in five southwestern states (18). However, the mechanisms underlying this relationship are not well understood. Extensive epidemiological research has linked NSES to vascular-related conditions $(4,19-22)$, poor health behaviors (23-25), and greater psychosocial stress (26-30). Incidentally, these factors also have well-established linkages with brain health such that individuals who have vascular-related conditions $(31,32)$, engage in lower physical activity, smoking and excessive alcohol intake (33-35), and have greater symptoms of depression or lower social support (36-38) experience increased risk for poor cognitive function. No studies to date have addressed whether these conditions may explain the relationship between NSES and cognitive function.

Prior studies indicate that neighborhood environments may influence poor cognitive function above and beyond individual-level demographic characteristics such as age, race/ ethnicity, educational attainment and income $(16,17,39,40)$. Demographic subgroups may be especially vulnerable to NSES' effects on cognitive function. Poor neighborhood environments may differentially affect older adults because they spend more time in their neighborhoods (41) and may have less access to social, financial, or health services, and have accumulated greater exposures to stressors or pollutants. Non-white older adults who live in lower SES neighborhoods may face discrimination or other stressors which may confer greater vulnerability to NSES effects on cognitive function. Wight and colleagues (17) examined individual- and neighborhood-level educational interaction among US adults. However, no U.S. study to date has addressed whether other individual-level demographic factors modify, or confer vulnerability to NSES using an index consisting of important measures of socioeconomic status beyond education alone.

The purpose of this study was to examine whether an NSES index was related to cognitive function in a large, geographically and demographically diverse cohort of older U.S. women with rich data on a sensitive measure of global cognitive function and a comprehensive set of clinical, behavioral and psychosocial confounders. We tested whether the relationship between NSES and cognitive function was explained by risk and protective factors for poor cognitive function that have also been linked with NSES, and whether certain subgroups were more vulnerable to lower NSES.

\section{METHODS}

Data Sources

The Women's Health Initiative Memory Study (WHIMS) was an ancillary study to the Women's Health Initiative hormone therapy trials (42), two large, randomized, doubleblind, placebo-controlled, clinical trials to assess the relative effect of $0.625 \mathrm{mg} /$ day of conjugated equine estrogen alone (E trial) or in combination with $2.5 \mathrm{mg} /$ day of continuous medroxyprogesterone acetate $(\mathrm{E}+\mathrm{P}$ trial) on the incidence of dementia and level of cognitive functioning in postmenopausal women. The study design, eligibility criteria and recruitment 
procedures of WHIMS have been described previously $(43,44)$. Briefly, 7,479 women from 39 sites who were at least 65 years of age and free of dementia were enrolled in WHIMS (4,532 in the E + P and 2,947 in the E trial) between May 1996 and December 1999. We geocoded addresses of WHIMS women at enrollment to the census tract and linked them with Census data on census tract-level NSES.

\section{Study Sample}

We excluded 1,342 women from the total sample (17.9 percent of 7,479): those living outside of Metropolitan Statistical Areas (MSAs; 797) which precluded us from accounting for geographic clustering, and those with missing, foreign, or military addresses, or with geocoded census tracts that were missing NSES values (545). A total of 6,137 women were included in the analyses. Women who were excluded from the analytic sample were slightly younger, less educated, and less wealthy. They were also more likely to be married, have more social support and social integration, be less depressed, and drink and smoke less (all $\chi^{2}$ p-values $\left.<0.05\right)$.

\section{Dependent Variable: Cognitive Function}

The Modified Mini-Mental State Examination (3MSE; (45)) measured cognitive functioning at baseline. The 3MSE is a well-established measure of global cognitive function with good reliability, and high sensitivity and specificity for detecting cognitive impairment and dementia in general and in WHIMS $(46,47)$. 3MSE assessments were administered by trained and certified technicians who were masked to treatment group and other outcomes. Administration times averaged 10-12 minutes. Total 3MSE score was a sum of 15 items and ranged 0-100; higher scores reflected better cognitive functioning. Test items measured temporal and spatial orientation, immediate and delayed recall, executive function (control and management of other cognitive processes), naming, verbal fluency, abstract reasoning, praxis, writing, and visuo-constructional abilities. Due to the skewed distribution towards higher 3MSE scores, a negative logarithmic transformation was applied [- $\log _{\mathrm{e}}(102-3 \mathrm{MSE}$ score)] to yield a more normal distribution. Higher transformed scores indicated higher cognitive functioning. We then computed z-scores from this index to express it in standard deviation units.

\section{Independent Variables: Neighborhood Socioeconomic Status}

NSES was assessed at the census tract level using data from the 2000 Census. NSES is an index of six census tract variables including: percent of adults older than 25 with education less than high school; percent male unemployment; percent of households with income below the poverty line; percent of households receiving public assistance; percent of households with children headed by a female; and median household income. The composite measure was identified through confirmatory factor analysis and demonstrated in prior studies to be an important neighborhood-level predictor of health outcomes (19). The NSES index was scaled to range 0-100 for U.S. census tracts; higher scores indicated more affluent tracts. To obtain the NSES value for each woman at baseline, which occurred between 1996 and 1999, we derived intercensal estimates using either geometric or linear interpolation based on the 1990 census tract definitions. Since some census tract boundaries changed between 1990 and 2000, we created a mapping between the 1990 and 2000 Censuses using the 1990/2000 Census Tract Relationship File to facilitate the interpolation.

\section{Independent Variables: Individual-level Covariates}

Individual-level demographic and lifestyle variables were measured at baseline by selfreport (44). To examine potential factors influencing the relationship between NSES and cognitive function, we considered three groups of confounders that have been previously 
linked with NSES or cognitive function. Vascular factors included non-fatal coronary heart disease (myocardial infarction, angina, and coronary revascularization), diabetes, stroke, or hypertension, as assessed by self-reported history, measured blood pressures, and current medication use. Health behaviors included the number of alcoholic drinks per day, smoking status, and physical activity (episodes per week of moderate activity lasting 20 or more minutes). Psychosocial factors included depressive symptoms, social support, and social integration as psychosocial confounders. Depressive symptoms were measured using a validated algorithm of an 8-item screening instrument (48) that incorporated 6 items from the Center for Epidemiological Studies Depression Scale (49) and 2 items from the Diagnostic Interview Scale (50). The total score ranged 0-1; higher scores indicated more depressive symptoms. Social support was measured by nine items selected from the Medical Outcomes Study (51). These assessed perceived availability of emotional/informational support, tangible support, affectionate support, and positive social interaction (sum $=9-45$ ). Social integration was an average of two items that measured how often a woman went to a religious service or meetings of clubs, lodges, or parent groups during the past month. Both items ranged 1 (not at all) to 6 (every day).

\section{Statistical Analysis}

We examined the cross-sectional association between NSES and transformed 3MSE scores at baseline. We used a linear mixed model with random effects to account for clustering by MSA. Exploratory analyses did not indicate that clustering by census tract improved model fit, whereas MSA-level clustering did. The model building strategy first examined the unadjusted relationship between NSES and 3MSE. Model 1 adjusted for basic demographic covariates that were significantly associated with NSES or cognitive function in bivariate regressions (median centered age, race/ethnicity, educational attainment, household income, and marital status). Hysterectomy status was included as a covariate because it distinguishes between women who were randomized to the $\mathrm{E}$ versus $\mathrm{E}+\mathrm{P}$ trial. A cutpoint of less than $\$ 10,000$ categorized household income because this appeared to define the strongest differences.

We then examined whether adjustment for three separate sets of confounders (Models 2-4) partially explained the association between NSES and 3MSE in Model 1. Model 2 included covariates from Model 1 and the vascular factors defined above. Model 3 included covariates from Model 1 and health behaviors. Model 4 included Model 1 covariates and psychosocial factors. Tests of interactions assessed the consistency of associations for subgroups of age ( $<70$ versus $\geq 70$ ), race (whites versus non-whites), household income (< $\$ 10,000$ versus $\$ \$ 10,000$ ), or educational status ( $\leq$ high school versus $\geq$ college). Individuallevel covariates for race/ethnicity, education, income, and marital status were missing in 6.7 percent of cases. Single imputation was used to impute missing values using IVEware (52). Supporting analyses, limited to women with complete data, were conducted to assess the sensitivity of findings to imputation.

\section{RESULTS}

\section{Baseline descriptive characteristics}

The baseline, raw mean 3MSE score was 95.1 for the 6,137 women in the analytic sample (Table 1). Approximately $87 \%$ of women were white, $7 \%$ were black, $3 \%$ were Hispanic and 3\% were of another race or ethnicity. Approximately $92 \%$ had a high school degree or higher, $51 \%$ were married, and 39\% had a hysterectomy. The mean NSES value across individual women in the sample was 75.4. Figure 1 illustrates the distribution of raw 3MSE scores by quartile of NSES where quartile cut-points are defined by the distribution of NSES in the WHIMS sample. 


\section{Cross-sectional association between NSES and cognitive function}

Table 2 displays coefficients and standard errors for the cross-sectional association between NSES and transformed 3MSE score. Without any covariate adjustment, living in a neighborhood with a one-unit higher NSES value (median NSES for the WHIMS sample $=77$; range $25-96$ ) was significantly associated with a 0.0235 standard deviations higher level of cognitive functioning $(p<0.001)$. The intraclass correlation was 0.052 . Once basic covariates were included (Model 1), this relationship remained significant (standardized $\beta=0.0037 ; p=0.02$ ). Adjustment for vascular factors (Model 2) attenuated the strength of the relationship slightly (standardized $\beta=0.0034 ; p=0.03$ ). Adjustment for health behavior factors (Model 3) or psychosocial factors (Model 4) also attenuated the relationship (standardized $\beta=0.0028 ; p=0.07$ and standardized $\beta=0.0028 ; p=0.08$, respectively). Coronary heart disease $(p=0.06)$ in Model 2 , alcohol intake $(p<0.001)$ in Model 3 and depressive symptoms $(p=0.03)$ in Model 4 were the only significant predictors of cognitive function after adjustment for NSES.

\section{Differences in NSES-3MSE Relationship Across Demographic Factors}

With minimal covariate adjustment (Model 1), the interaction between NSES and age was significant at $p=0.05$ and with race was marginally statistically significant $(p=0.07)$. As portrayed in Figure 2, the fitted slopes were greater for younger versus older women and for non-white versus white women. Adjustment for vascular, health behavior, and psychosocial factors in Models 2-4 did not materially change these results. There was no evidence that relationships varied among subgroups defined by household income and education $(p>0.10)$. Sensitivity analyses among only women who had complete, non-imputed data yielded similar results for the analyses among the full sample. Stratified analyses were similar, although the only difference was that education-stratified analyses among the reduced sample without imputed data revealed a stronger association between higher NSES and higher cognitive function among women with higher education $(p<0.05)$.

\section{DISCUSSION}

This study of a national sample of older U.S. women provides consistent evidence that living in a neighborhood with higher NSES is associated with higher cognitive functioning, above and beyond individual-level demographic characteristics such as age, race/ethnicity, income, education, and marital status. This is the largest U.S.-based study to examine the cross-sectional relationship between area-level socioeconomic composition and cognitive function, and to explore potential underlying mechanisms as well as vulnerability to NSES across age, race, income, and education.

We hypothesized that the relationship between higher NSES and higher cognitive function in women would be explained by the association between NSES and vascular factors, health behavior, and psychosocial factors. These factors only partially explained the relationship between NSES and cognitive function, as indicated by the slightly smaller magnitudes of regression parameters. In particular, the results for the overall sample indicated that adjustment for health behavior and psychosocial factors resulted in the greatest relative reduction in the association between NSES and cognitive function. However, accounting for the three groups of confounders did not completely explain the relationship suggesting that there may be other factors that have not been accounted for. These may include better access to high-quality health services, cognitive activity, or intake of foods high in antioxidants that have been shown to be protective against poor cognitive function (53-56).

These findings corroborate prior research on NSES and cognitive function. Lang and colleagues (16) found that higher neighborhood socioeconomic deprivation was cross- 
sectionally related to lower cognitive functioning. Further adjustment for systolic blood pressure, stroke, and depression did not account for the association between neighborhood deprivation and cognitive function. Accounting for perceived access to medical resources or stores and local shops also did not account for the association. Wight and colleagues (17) found that lower neighborhood-level education was cross-sectionally associated with lower cognitive performance, even after adjustment for demographic factors, depressive symptoms, and chronic health conditions. While these studies were nationally representative of U.K. adults 52 and older (16) or U.S. adults older than 70 (17), our study adds to the literature by including rural, in addition to urban or suburban areas, and also by measuring cognitive functioning using the $3 \mathrm{MSE}$ which is more sensitive to detecting cognitive impairment than tests used in those studies $(57,58)$.

We hypothesized that the relationship between higher NSES and higher cognitive function would be more pronounced for non-white and older women, and women with lower individual SES. However, stratified analyses and models with interaction terms indicated that higher NSES was protective for younger and non-white women. Individual-level income and education did not modify the effects of NSES. Lang and colleagues (16) found that neighborhood deprivation's association with poor cognition was more pronounced among older men and women. Our findings, which can also be interpreted as an association between lower NSES and lower cognitive function for younger and non-white women, conflict with the findings of Lang and colleagues. Our results do not support prior literature that suggests older individuals are more vulnerable to lower NSES neighborhood effects due to a longer duration of exposure to poor or declining neighborhood conditions, greater acquired biological and psychological and cognitive vulnerability, general declines in physical function that may limit their mobility to areas outside of their neighborhood, and greater reliance on local health and social resources $(41,59)$. It is unclear why older women in WHIMS were not as vulnerable to effects of living in a lower SES neighborhood; it may be that older women in WHIMS were exposed to unmeasured factors accumulated over the lifetime which may have overwhelmed the effects of NSES on cognition. Additionally, survivorship bias may play a role if women living in lower SES neighborhoods have worse cognitive function and experience higher mortality rates than those with better cognitive function. Both of these hypotheses should be examined further. Nonetheless, our findings suggest that it may not be too early to intervene in women younger than age 70 to mitigate the effects of lower NSES on risk for lower cognitive function. Discrepant findings may be due to the fact that Lang and colleagues (16) may have included women with dementia. In addition, the variability of NSES in the WHIMS sample was greater in the younger age group compared to the older age group, which may have promoted our ability to detect a relationship among the younger age group. Because the WHIMS does not have data on duration of current residence, we cannot rule out the possibility that older women may have been more likely to move recently, and therefore live in a neighborhood with a different NSES than the neighborhoods they spent most of their lives in. This bias would be most relevant if NSES has a more acute effect. However, research indicates that neighborhoods are slow to change over time, and the differences in neighborhoods that individuals live in do not change drastically over the life course $(3,60,61)$.

This study is the first to report differences in the relationship between NSES and cognitive function by race. Our results concur with our hypothesis that non-whites may be more vulnerable to NSES effects compared to whites due to greater susceptibility to the effects of stressors, or have lower access to social, psychosocial, and economic resources. It is possible that the ability to observe this association was facilitated by the larger variance in NSES values among non-whites compared to whites. While Wight and colleagues (17) found that the effect of living in a neighborhood with lower educational attainment on cognitive performance was modified by individual-level education, we did not find significant effect 
modification by education, although we did find a stronger effect among those with higher education in sensitivity analyses that excluded imputed data. Women excluded from the analytic sample were less educated suggesting that the association among women with lower education may be more sensitive to missing data.

Our data are drawn from non-demented volunteers who were eligible for a trial of postmenopausal hormone therapy, yet we still observed a robust association between NSES and 3MSE after adjustment for vascular factors, and a reduced association after adjustment for health behavior and psychosocial factors. Without covariate adjustment, a two standard deviation difference in NSES (i.e. 17 units) was associated with an approximately 0.4 standard deviation difference $(17 * 0.0235)$ in our measure of cognitive function. Covariate adjustment for potential confounders in Models 1-4 attenuated this relationship so that a two standard deviation NSES differences was associated with 0.04 to $0.06(17 * 0.0022$ and $17 * 0.0037$, respectively) standard deviation differences in cognitive function. To provide some context for comparison purposes, the WHIMS trials found assignment to conjugated equine estrogen therapy without or with medroxyprogesterone acetate was associated with decrements in cognitive function of 0.08 to 0.09 standard deviations, respectively, over the course of the trials (62), and these relatively small mean differences were associated with significant increases in dementia and brain atrophy $(43,63,64)$.

This study has a number of important strengths. First, this is the largest U.S. study of contextual-level socioeconomic status on cognitive function. Second, our primary outcome measure, the 3MSE, is a widely used measure of global cognitive function and screening tool of dementia that covers a wider range of cognitive domains (65), difficulty of items, and sensitivity to cognitive impairment compared to other tests of global cognitive function (45). Third, the WHIMS encompasses a demographically and geographically diverse sample of women living in 35 states and rural, mixed, and urban areas (3\%, 76\%, 21\%, respectively, of all sample tracts), lending further support for a contextual-level effect on cognitive function in the U.S. Although we excluded women living outside MSAs, some MSAs include rural and mixed rural-urban census tracts. Our study also expands upon one other U.S.-based national study (17) by including women younger than 70 years. Fourth, we examined a comprehensive and multi-faceted index of socioeconomic status which builds on prior literature $(17,39)$ that has focused on education or income, or classes of neighborhoods (barrio, transitional, or suburban). Lastly, we considered a relatively large number of confounders to examine potential mechanistic pathways. Inclusion of these confounders indicated that higher NSES was independently and consistently associated with cognitive functioning, even after accounting for important demographic, vascular, health behavior, and psychosocial confounders.

Despite these strengths, we note several limitations of these analyses. We examined crosssectional associations between NSES, cognitive function, and confounding variables measured at baseline. Thus, any causal relationships or indication of mediation resulting from the adjustment for vascular, health behavior, and psychosocial covariates, and examination of the reduction of main effects (66) must be interpreted with caution. The WHIMS is not a population-based sample and included mostly well-educated women who had volunteered and were eligible for a clinical trial of postmenopausal hormone therapy, and probably had substantial interest in their health. It also required participants to have plans to stay in their current geographic area so these results may not be generalizable to other populations, including men. The generalizability of the sample may have been further restricted by missing NSES data or information on MSAs, limiting it to $82 \%$ of the entire WHIMS cohort. In addition, we cannot rule out the potential for residual confounding or selection effects such that individuals with similar characteristics beyond those we accounted for may systematically choose to live in similar neighborhoods. 
Poor cognitive function in late life has been linked with steeper declines in cognitive function over time, which increases the risk of dementia such as Alzheimer's disease (67, 68). Our analyses suggest that policies that aim to bolster higher NSES, or early public health interventions that target modifiable risk factors such as poor health behaviors and facilitate social support and integration among women in lower SES neighborhoods, may also provide some protection against the harmful effects of NSES on poor cognitive function. In particular, the relationship between living in a lower SES neighborhood and moderate alcohol intake or more depressive symptoms indicates that these may be key intermediate factors to intervene on for individuals living in high-risk neighborhoods. Stratified analyses showing differential effects by age and race indicate that targeted interventions among non-white women or women younger than 70 may help mitigate the harmful effects of lower NSES. Future research should examine the longitudinal relationship between living in a lower SES neighborhood and risk for steeper cognitive declines and risk for subclinical syndromes that increase risk for dementia such as mild cognitive impairment.

\section{Acknowledgments}

This work was funded by a grant from the National Heart, Lung and Blood Institute (NHLBI; 1-R01-HL084425) to C.E.B. The WHI program is funded by the NHLBI, National Institutes of Health, U.S. Department of Health and Human Services through contracts N01WH22110, 24152, 32100-2, 32105-6, 32108-9, 32111-13, 32115, 32118-32119, 32122, 42107-26, 42129-32, and 44221. The project was reviewed by the Institution's IRB, the WHI Design and Analysis Advisory Committee, the WHI Steering Committee and the WHI Project Office. This work was presented at the American Association of Geriatric Psychiatry's Annual Conference in San Antonio, TX on March 20, 2011

The authors acknowledge the contributions of WHI Investigators in the:

Program Office: (National Heart, Lung, and Blood Institute, Bethesda, Maryland) Jacques Rossouw, Shari Ludlam, Joan McGowan, Leslie Ford, and Nancy Geller.

Clinical Coordinating Center: (Fred Hutchinson Cancer Research Center, Seattle, WA) Ross Prentice, Garnet Anderson, Andrea LaCroix, Charles L. Kooperberg; (Medical Research Labs, Highland Heights, KY) Evan Stein; (University of California at San Francisco, San Francisco, CA) Steven Cummings.

Clinical Centers: (Albert Einstein College of Medicine, Bronx, NY) Sylvia Wassertheil- Smoller; (Baylor College of Medicine, Houston, TX) Haleh Sangi-Haghpeykar; (Brigham and Women's Hospital, Harvard Medical School, Boston, MA) JoAnn E. Manson; (Brown University, Providence, RI) Charles B. Eaton; (Emory University, Atlanta, GA) Lawrence S. Phillips; (Fred Hutchinson Cancer Research Center, Seattle, WA) Shirley Beresford; (George Washington University Medical Center, Washington, DC) Lisa Martin; (Los Angeles Biomedical Research Institute at Harbor- UCLA Medical Center, Torrance, CA) Rowan Chlebowski; (Kaiser Permanente Center for Health Research, Portland, OR) Erin LeBlanc; (Kaiser Permanente Division of Research, Oakland, CA) Bette Caan; (Medical College of Wisconsin, Milwaukee, WI) Jane Morley Kotchen; (MedStar Research Institute/Howard University, Washington, DC) Barbara V. Howard; (Northwestern University, Chicago/Evanston, IL) Linda Van Horn; (Rush Medical Center, Chicago, IL) Henry Black; (Stanford Prevention Research Center, Stanford, CA) Marcia L. Stefanick; (State University of New York at Stony Brook, Stony Brook, NY) Dorothy Lane; (The Ohio State University, Columbus, $\mathrm{OH}$ ) Rebecca Jackson; (University of Alabama at Birmingham, Birmingham, AL) Cora E. Lewis; (University of Arizona, Tucson/Phoenix, AZ) Cynthia A. Thomson; (University at Buffalo, Buffalo, NY) Jean Wactawski-Wende; (University of California at Davis, Sacramento, CA) John Robbins; (University of California at Irvine, CA) F. Allan Hubbell; (University of California at Los Angeles, Los Angeles, CA) Lauren Nathan; (University of California at San Diego, LaJolla/Chula Vista, CA) Robert D. Langer; (University of Cincinnati, Cincinnati, OH) Margery Gass; (University of Florida, Gainesville/Jacksonville, FL) Marian Limacher; (University of Hawaii, Honolulu, HI) J. David Curb; (University of Iowa, Iowa City/Davenport, IA) Robert Wallace; (University of Massachusetts/Fallon Clinic, Worcester, MA) Judith Ockene; (University of Medicine and Dentistry of New Jersey, Newark, NJ) Norman Lasser; (University of Miami, Miami, FL) Mary Jo O'Sullivan; (University of Minnesota, Minneapolis, MN) Karen Margolis; (University of Nevada, Reno, NV) Robert Brunner; (University of North Carolina, Chapel Hill, NC) Gerardo Heiss; (University of Pittsburgh, Pittsburgh, PA) Lewis Kuller; (University of Tennessee Health Science Center, Memphis, TN) Karen C. Johnson; (University of Texas Health Science Center, San Antonio, TX) Robert Brzyski; (University of Wisconsin, Madison, WI) Gloria E. Sarto; (Wake Forest University School of Medicine, Winston-Salem, NC) Mara Vitolins; (Wayne State University School of Medicine/Hutzel Hospital, Detroit, MI) Michael S. Simon. 


\section{References}

1. Anderson RT, Sorlie P, Backlund E, Johnson N, Kaplan GA. Mortality effects of community socioeconomic status. Epidemiology. 1997; 8(1):42-7. [PubMed: 9116094]

2. Cubbin C, Winkleby MA. Protective and harmful effects of neighborhood-level deprivation on individual-level health knowledge, behavior changes, and risk of coronary heart disease. American Journal of Epidemiology. 2005; 162(2):559-568. [PubMed: 16093286]

3. Diez Roux AV. Investigating neighborhood and area effects on health. Am J Public Health. 2001; 91(11):1783-9. [PubMed: 11684601]

4. Diez-Roux AV, Nieto FJ, Muntaner C, Tyroler HA, Comstock GW, Shahar E, et al. Neighborhood environments and coronary heart disease: a multilevel analysis. Am J Epidemiol. 1997; 146(1):4863. [PubMed: 9215223]

5. Feldman PJ, Steptoe A. How neighborhoods and physical functioning are related: the roles of neighborhood socioeconomic status, perceived neighborhood strain, and individual health risk factors. Ann of Behav Med. 2004; 27(2):91-99. [PubMed: 15026293]

6. Haan M, Kaplan GA, Camacho T. Poverty and health. Prospective evidence from the Alameda County Study. Am J Epidemiol. 1987; 125(6):989-98. [PubMed: 3578257]

7. Jones K, Duncan C. Individuals and their ecologies: analysing the geography of chronic illness within a multilevel modeling framework. Health and Place. 1995; 1:27-30.

8. Leclere F, Rogers R, Peters K. Ethnicity and Mortality in the United States: Individual and Community Correlates. Social Forces. 1997; 76:769-798.

9. Lochner KA, Kawachi I, Brennan RT, Buka SL. Social capital and neighborhood mortality rates in Chicago. Soc Sci Med. 2003; 56(8):1797-805. [PubMed: 12639596]

10. Robert SA. Community-Level Socioeconomic Status Effects on Adult Health. Journal of Health and Social Behavior. 1998; 39:18-37. [PubMed: 9575702]

11. Ross CE, Mirowsky J. Neighborhood disadvantage, disorder, and health. J Health Soc Behav. 2001; 42(3):258-76. [PubMed: 11668773]

12. Singh GK, Siahpush M. Increasing inequalities in all-cause and cardiovascular mortality among US adults aged 25-64 years by area socioeconomic status, 1969-1998. Int J Epidemiol. 2002; 31(3):600-13. [PubMed: 12055162]

13. Sundquist K, Malmstrom M, Johansson SE. Neighbourhood deprivation and incidence of coronary heart disease: a multilevel study of 2. 6 million women and men in Sweden. J Epidemiol Community Health. 2004; 58(1):71-7. [PubMed: 14684730]

14. Wainwright NW, Surtees PG. Places, people, and their physical and mental functional health. J Epidemiol Community Health. 2004; 58(4):333-9. [PubMed: 15026450]

15. Yen IH, Syme SL. The social environment and health: a discussion of the epidemiologic literature. Annu Rev Public Health. 1999; 20:287-308. [PubMed: 10352860]

16. Lang IA, Llewellyn DJ, Langa KM, Wallace RB, Huppert FA, Melzer D. Neighborhood deprivation, individual socioeconomic status, and cognitive function in older people: analyses from the English Longitudinal Study of Ageing. J Am Geriatr Soc. 2008; 56(2):191-8. [PubMed: 18179489]

17. Wight RG, Aneshensel CS, Miller-Martinez D, Botticello AL, Cummings JR, Karlamangla AS, et al. Urban neighborhood context, educational attainment, and cognitive function among older adults. Am J Epidemiol. 2006; 163(12):1071-8. [PubMed: 16707655]

18. Sheffield KM, Peek MK. Neighborhood context and cognitive decline in older Mexican Americans: results from the Hispanic Established Populations for Epidemiologic Studies of the Elderly. Am J Epidemiol. 2009; 169(9):1092-101. [PubMed: 19270047]

19. Bird CE, Shih RA, Eibner C, Griffin BA, Slaughter ME, Whitsel E, et al. Neighborhood socioeconomic status and incident coronary heart disease among women. J Gen Intern Med. 2009; 24(Suppl 1):S127.

20. Sundquist K, Winkleby M, Ahlen H, Johansson SE. Neighborhood Socioeconomic Environment and Incidence of Coronary Heart Disease: A Follow-up Study of 25,319 Women and Men in Sweden. American Journal of Epidemiology. 2004; 159(7):655-662. [PubMed: 15033643] 
21. Winkleby M, Sundquist K, Cubbin C. Inequities in CHD incidence and case fatality by neighborhood deprivation. Am J Prev Med. 2007; 32(2):97-106. [PubMed: 17234484]

22. Nordstrom CK, Diez Roux AV, Jackson SA, Gardin JM. The association of personal and neighborhood socioeconomic indicators with subclinical cardiovascular disease in an elderly cohort. The cardiovascular health study. Soc Sci Med. 2004; 59(10):2139-47. [PubMed: 15351479]

23. Boardman JD, Finch BK, Ellison CG, Williams DR, Jackson JS. Neighborhood disadvantage, stress, and drug use among adults. J Health Soc Behav. 2001; 42(2):151-65. [PubMed: 11467250]

24. Dubowitz T, Heron M, Bird CE, Lurie N, Finch BK, Basurto-Dávila R, et al. Neighborhood socioeconomic status and fruit and vegetable intake among whites, blacks, and Mexican Americans in the United States. Am J Clin Nutr. 2008; 87(6):1883-91. [PubMed: 18541581]

25. Moore LV, Diez Roux AV. Associations of neighborhood characteristics with the location and type of food stores. Am J Public Health. 2006; 96(2):325-31. [PubMed: 16380567]

26. Cutrona CE, Wallace G, Wesner KA. Neighborhood Characteristics and Depression: An Examination of Stress Processes. Curr Dir Psychol Sci. 2006; 15(4):188-192. [PubMed: 18185846]

27. Sampson RJ, Morenoff JD, Gannon-Rowley T. Assessing “neighborhood effects:” Social processes and new directions in research. Ann Rev Soc. 2002; 28:443-478.

28. Wickrama KA, Conger RD, Wallace LE, Elder GH Jr. Linking early social risks to impaired physical health during the transition to adulthood. J Health Soc Behav. 2003; 44(1):61-74. [PubMed: 12751311]

29. Aneshensel CS, Wight RG, Miller-Martinez D, Botticello AL, Karlamangla AS, Seeman TE. Urban neighborhoods and depressive symptoms among older adults. J Gerontol B Psychol Sci Soc Sci. 2007; 62(1):S52-9. [PubMed: 17284567]

30. Mair CF, Diez Roux A, Galea S. Are Neighborhood Characteristics Associated with Depressive Symptoms? A Critical Review. J Epidemiol Comm Health. 2008; 6:940-46.

31. Cacciatore F, Abete P, Ferrara N, Calabrese C, Napoli C, Maggi S, et al. Congestive heart failure and cognitive impairment in an older population. Osservatorio Geriatrico Campano Study Group. J Am Geriatr Soc. 1998; 46(11):1343-8. [PubMed: 9809754]

32. Di Carlo A, Baldereschi M, Amaducci L, Maggi S, Grigoletto F, Scarlato G, et al. Cognitive impairment without dementia in older people: prevalence, vascular risk factors, impact on disability. The Italian Longitudinal Study on Aging. J Am Geriatr Soc. 2000; 48(7):775-82. [PubMed: 10894316]

33. Espeland MA, Coker LH, Wallace R, Rapp SR, Resnick SM, Limacher M, et al. Association between alcohol intake and domain-specific cognitive function in older women. Neuroepidemiology. 2006; 27(1):1-12. [PubMed: 16717476]

34. Ott A, Andersen K, Dewey ME, Letenneur L, Brayne C, Copeland JR, et al. Effect of smoking on global cognitive function in nondemented elderly. Neurology. 2004; 62(6):920-4. [PubMed: 15037693]

35. Sabia S, Nabi H, Kivimaki M, Shipley MJ, Marmot MG, Singh-Manoux A. Health behaviors from early to late midlife as predictors of cognitive function: The Whitehall II study. Am J Epidemiol. 2009; 170(4):428-37. [PubMed: 19574344]

36. Chodosh J, Kado DM, Seeman TE, Karlamangla AS. Depressive symptoms as a predictor of cognitive decline: MacArthur Studies of Successful Aging. Am J Geriatr Psychiatry. 2007; 15(5): 406-15. [PubMed: 17353297]

37. Ganguli M, Du Y, Dodge HH, Ratcliff GG, Chang CC. Depressive symptoms and cognitive decline in late life: a prospective epidemiological study. Arch Gen Psychiatry. 2006; 63(2):15360. [PubMed: 16461857]

38. Seeman TE, Lusignolo TM, Albert M, Berkman L. Social relationships, social support, and patterns of cognitive aging in healthy, high-functioning older adults: MacArthur studies of successful aging. Health Psychol. 2001; 20(4):243-55. [PubMed: 11515736]

39. Espino DV, Lichtenstein MJ, Palmer RF, Hazuda HP. Ethnic differences in mini-mental state examination (MMSE) scores: where you live makes a difference. J Am Geriatr Soc. 2001; 49(5): 538-48. [PubMed: 11380745] 
40. George, LK.; Landerman, LR.; Blazer, DG. Cognitive impairment. In: Robbins, LN.; Regier, DA., editors. Psychiatric Disorders in America. New York: Free Press; 1991. p. 291-327.

41. Cagney KA, Browning CR, Wen M. Racial disparities in self-rated health at older ages: what difference does the neighborhood make? J Gerontol B Psychol Sci Soc Sci. 2005; 60(4):S181-90. [PubMed: 15980292]

42. Stefanick ML, Cochrane BB, Hsia J, Barad DH, Liu JH, Johnson SR. The Women's Health Initiative postmenopausal hormone trials: overview and baseline characteristics of participants. Ann Epidemiol. 2003; 13(9 Suppl):S78-86. [PubMed: 14575940]

43. Shumaker SA, Reboussin BA, Espeland MA, Rapp SR, McBee WL, Dailey M, et al. The Women's Health Initiative Memory Study (WHIMS): a trial of the effect of estrogen therapy in preventing and slowing the progression of dementia. Control Clin Trials. 1998; 19(6):604-21. [PubMed: 9875839]

44. Shumaker SA, Legault C, Kuller L. Conjugated equine estrogen alone, pooled hormone therapy, and incidence of probable dementia and mild cognitive impairment in postmenopausal women. JAMA. 2004; 291:2947-2958. [PubMed: 15213206]

45. Teng EL, Chui HC. The Modified Mini-Mental State (3MS) examination. J Clin Psychiatry. 1987; 48(8):314-8. [PubMed: 3611032]

46. Bland RC, Newman SC. Mild dementia or cognitive impairment: the Modified Mini-Mental State examination (3MS) as a screen for dementia. Can J Psychiatry. 2001; 46(6):506-10. [PubMed: 11526806]

47. Espeland MA, Rapp SR, Robertson J, Granek I, Murphy C, Albert M, et al. Benchmarks for designing two-stage studies using modified mini-mental state examinations: experience from the Women's Health Initiative Memory Study. Clin Trials. 2006; 3(2):99-106. [PubMed: 16773952]

48. Tuunainen A, Langer RD, Klauber MR, Kripke DF. Short version of the CES-D (Burnam screen) for depression in reference to the structured psychiatric interview. Psychiatry Res. 2001; 103(2-3): 261-70. [PubMed: 11549413]

49. Radloff LS. The CES-D Scale: a self-report depression scale for research in the general population. Applied Psychological Measurement. 1977; 1(3):385-401.

50. Robins LN, Helzer JE, Croughan J, Ratcliff KS. National Institute of Mental Health Diagnostic Interview Schedule. Its history, characteristics, and validity. Arch Gen Psychiatry. 1981; 38(4): 381-9. [PubMed: 6260053]

51. Sherbourne CD, Stewart AL. The MOS social support survey. Soc Sci Med. 1991; 32(6):705-14. [PubMed: 2035047]

52. Raghunathan, TE.; Solenberger, PW.; van Hoewyk, J. IVEware: imputation and variance estimation software userguide. 2002.

53. Altschuler A, Somkin CP, Adler NE. Local services and amenities, neighborhood social capital, and health. Soc Sci Med. 2004; 59(6):1219-29. [PubMed: 15210093]

54. Carlson MC, Saczynski JS, Rebok GW, Seeman T, Glass TA, McGill S, et al. Exploring the effects of an "everyday" activity program on executive function and memory in older adults: Experience Corps. Gerontologist. 2008; 48(6):793-801. [PubMed: 19139252]

55. Joseph JA, Shukitt-Hale B, Willis LM. Grape juice, berries, and walnuts affect brain aging and behavior. J Nutr. 2009; 139(9):1813S-7S. [PubMed: 19640963]

56. Wengreen HJ, Munger RG, Corcoran CD, Zandi P, Hayden KM, Fotuhi M, et al. Antioxidant intake and cognitive function of elderly men and women: the Cache County Study. J Nutr Health Aging. 2007; 11(3):230-7. [PubMed: 17508099]

57. McDowell I, Kristjansson B, Hill GB, Hebert R. Community screening for dementia: the Mini Mental State Exam (MMSE) and Modified Mini-Mental State Exam (3MS) compared. J Clin Epidemiol. 1997; 50(4):377-83. [PubMed: 9179095]

58. Tombaugh TN, McIntyre NJ. The mini-mental state examination: a comprehensive review. J Am Geriatr Soc. 1992; 40(9):922-35. [PubMed: 1512391]

59. Glass, TA.; Balfour, JL. Neighborhoods, aging, and functional limitations. In: Kawachi, I.; Berkman, L., editors. Neighborhoods and Health. Oxford: Oxford University Press; 2003. p. 303-334. 
60. Geronimus AT, Bound J. Use of census-based aggregate variables to proxy for socioeconomic group: evidence from national samples. Am J Epidemiol. 1998; 148(5):475-86. [PubMed: 9737560]

61. Grafova IB, Freedman VA, Kumar R, Rogowski J. Neighborhoods and obesity in later life. American Journal of Public Health. 2008; 98(11):2065-71. [PubMed: 18799770]

62. Espeland MA, Brunner RL, Hogan PE. Long-term effects of conjugated equine estrogen therapies on domain-specific cognitive function. J Am Geriatr Soc. 2010; 58:1263-1271. [PubMed: 20649689]

63. Resnick SR, Espeland MA, Jaramillo SA. Effects of postmenopausal hormone therapy on regional brain volumes in older women. Neurology. 2009; 72:135-142. [PubMed: 19139364]

64. Espeland MA, Tindle HA, Bushnell CA. Brain volumes, cognitive impairment, and conjugated equine estrogens. J Gerontol A Biol Sci Med. 2009; 64(12):1243-1250.

65. Cullen M, O’Neil B, Evans JJ, Coen RF, Lawlor BA. A review of screening tests for cognitive impairment. J Neurol Neurosurg Psychiatry. 2007; 78(8):790-799. [PubMed: 17178826]

66. Baron RM, Kenny DA. The moderator-mediator variable distinction in social psychological research: conceptual, strategic, and statistical considerations. J Pers Soc Psychol. 1986; 51(6): 1173-82. [PubMed: 3806354]

67. Backman L, Jones S, Berger AK, Laukka EJ, Small BJ. Multiple cognitive deficits during the transition to Alzheimer's disease. J Intern Med. 2004; 256(3):195-204. [PubMed: 15324363]

68. Jones S, Small BJ, Fratiglioni L, Backman L. Predictors of cognitive change from preclinical to clinical Alzheimer's disease. Brain Cogn. 2002; 49(2):210-3. [PubMed: 15259392] 


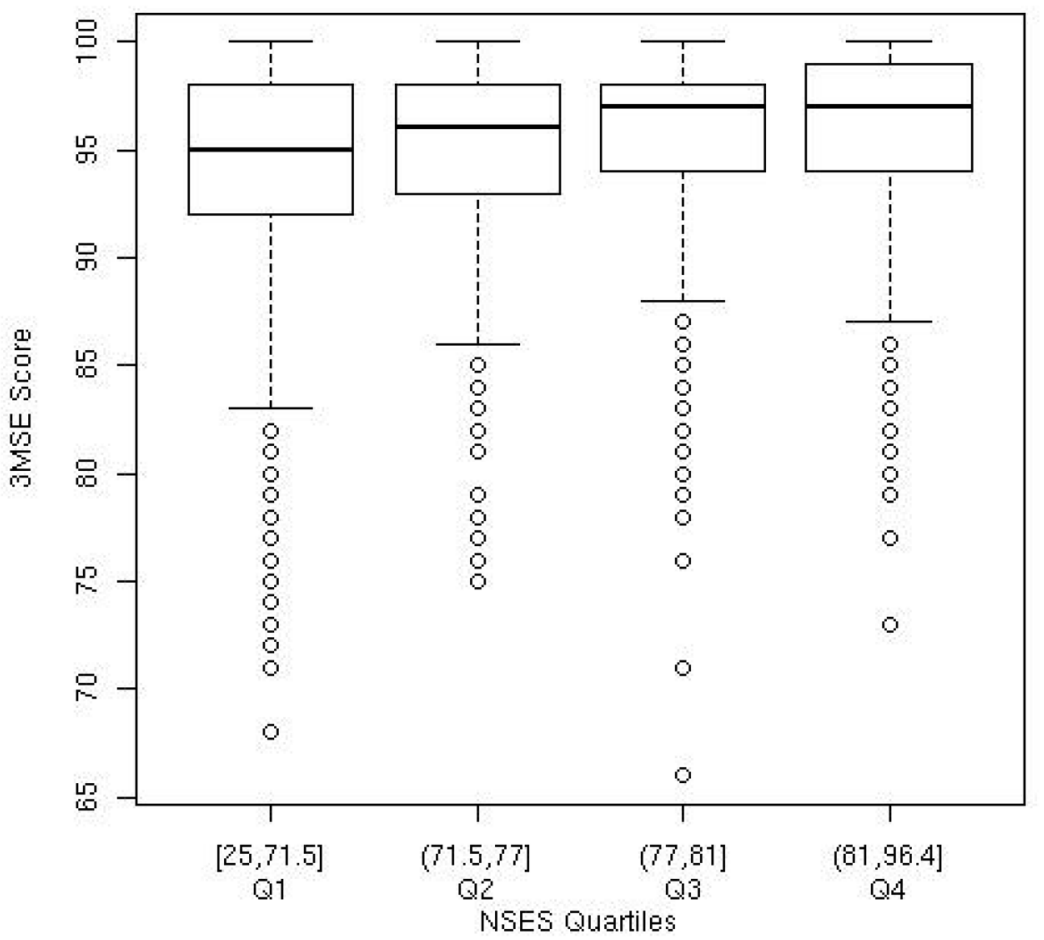

Figure 1.

Box Plot Graphs of Raw Modified Mini-Mental Examination Score (3MSE) by Neighborhood Socioeconomic Status (NSES) Quartile. 


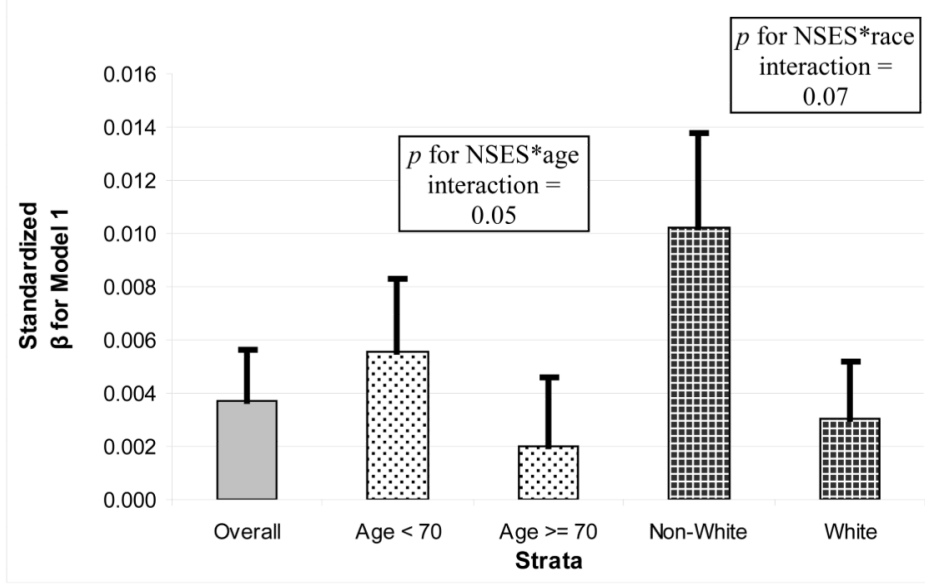

Figure 2. NSES and Global Cognitive Function: Linear Regression Parameter Estimates (Margin of Error) for Overall Sample, and Stratified by Individual-level Age and Race Notes: Global cognitive function is measured by the Modified Mini-Mental Examination Score (3MSE); NSES=Census tract-level neighborhood socioeconomic status; White = nonHispanic Caucasian; Global cognitive function is scaled in standard deviation units of [- $\log _{\mathrm{e}}(102-3 \mathrm{MSE}$ score $\left.)\right]$.

Model 1 adjusts for basic covariates (centered-median age, race/ethnicity, educational attainment, household income, marital status, and hysterectomy status) 
Table 1

Baseline Sample Characteristics $(\mathrm{N}=6,137)$

\begin{tabular}{|c|c|}
\hline Variable & Mean (SD) or n (\%) \\
\hline 3MSE score & $95.1(4.4)$ \\
\hline \multicolumn{2}{|c|}{ Individual-level characteristics } \\
\hline Age & $70.2(3.9)$ \\
\hline \multicolumn{2}{|l|}{ Race/ethnicity } \\
\hline Non-Hispanic White & $5337(87 \%)$ \\
\hline Non-Hispanic Black & $429(7 \%)$ \\
\hline Hispanic & $157(2.6 \%)$ \\
\hline Other & $214(3.5 \%)$ \\
\hline \multicolumn{2}{|l|}{ Educational attainment } \\
\hline Less than high school & $472(7.7 \%)$ \\
\hline High school graduate & $1358(22.1 \%)$ \\
\hline Some college & $2426(39.5 \%)$ \\
\hline College degree or higher & $1881(30.7 \%)$ \\
\hline \multicolumn{2}{|l|}{ Household income } \\
\hline Less than $\$ 10,000$ & $354(5.8 \%)$ \\
\hline$\$ 10,000$ to $\$ 19,999$ & $1176(19.2 \%)$ \\
\hline$\$ 20,000$ to $\$ 34,999$ & $1889(30.8 \%)$ \\
\hline$\$ 35,000$ to $\$ 49,999$ & $1282(20.9 \%)$ \\
\hline$\$ 50,000$ to $\$ 74,999$ & $915(14.9 \%)$ \\
\hline$\$ 75,000$ to $\$ 99,999$ & $305(5 \%)$ \\
\hline$\$ 100,000$ to $\$ 149,999$ & $150(2.4 \%)$ \\
\hline$\$ 150,000$ or more & $66(1.1 \%)$ \\
\hline \multicolumn{2}{|l|}{ Marital status } \\
\hline Never married & $218(3.6 \%)$ \\
\hline Divorced or separated & $781(12.7 \%)$ \\
\hline Widowed & $1930(31.4 \%)$ \\
\hline Marriage-like relationship & $52(0.8 \%)$ \\
\hline Married & $3156(51.4 \%)$ \\
\hline
\end{tabular}

Hysterectomy status

No

$3744(61 \%)$

Yes

$2393(39 \%)$

Vascular factors

History of or current coronary heart disease

$588(9.6 \%)$

History of or current stroke

$103(1.7 \%)$

History of or current diabetes

$518(8.4 \%)$

History of or current hypertension

$3289(53.6 \%)$

\section{Health behavior factors}

Alcohol intake 


\begin{tabular}{|c|c|}
\hline Variable & Mean (SD) or n (\%) \\
\hline No intake & $2729(44.5 \%)$ \\
\hline$<1$ drink/day & $2735(44.6 \%)$ \\
\hline 1 or more drinks / day & $673(11 \%)$ \\
\hline \multicolumn{2}{|l|}{ Smoking Status } \\
\hline Never smoked & $3170(51.7 \%)$ \\
\hline Past smoker & $2501(40.8 \%)$ \\
\hline Current smoker & $466(7.6 \%)$ \\
\hline \multicolumn{2}{|l|}{ Physical activity } \\
\hline No activity & $1095(17.8 \%)$ \\
\hline Some activity of limited duration, frequency, or intensity & $2752(44.8 \%)$ \\
\hline 2 to 3 times/week ${ }^{\dagger}$ & $981(16 \%)$ \\
\hline$\geq 4$ times/week ${ }^{\dagger}$ & $1293(21.1 \%)$ \\
\hline \multicolumn{2}{|l|}{ Psychosocial factors } \\
\hline Depressive symptoms & $0.03(0.1)$ \\
\hline Social support & $35.5(7.9)$ \\
\hline Social integration & $2.6(1.1)$ \\
\hline NSES $^{\neq}$ & $75.4(8.5)$ \\
\hline
\end{tabular}

Notes: 3MSE=Modified Mini-Mental Examination Score; NSES=Census tract-level neighborhood socioeconomic status 


\section{Table 2}

Standardized Linear Regression Parameter Estimates (SE) for the Association Between Neighborhood Socioeconomic Status (NSES) and Global Cognitive Function

\begin{tabular}{ll}
\hline & Standardized $\beta(\mathrm{SE})$ \\
Unadjusted & $0.0235(0.0015){ }^{* * *}$ \\
Model 1 & $0.0037(0.0017)^{* *}$ \\
Model 2 & $0.0034(0.0017)^{* *}$ \\
Model 3 & $0.0028(0.0017)^{*}$ \\
Model 4 & $0.0028(0.0017)^{*}$ \\
\hline
\end{tabular}

Notes: Global cognitive function is measured by the Modified Mini-Mental Examination Score; Global cognitive function is scaled in standard deviation units of [- $\log _{\mathrm{e}}(102-3 \mathrm{MSE}$ score $\left.)\right]$; Neighborhood socioeconomic status is measured at the census tract-level.

Model 1 adjusts for basic covariates (centered-median age, race/ethnicity, educational attainment, household income, marital status, and hysterectomy status)

Model 2 includes basic covariates + vascular factors (history of or current coronary heart disease, diabetes, stroke, and hypertension)

Model 3 includes basic covariates + behavior factors (alcohol intake, smoking status, and physical activity)

Model 4 includes basic covariates + psychosocial factors (depressive symptoms, social support, and social integration)

*

* $p \leq 0.10$

*** $\leq 0.05$;

**** $p \leq 0.01$ 